\title{
SOBRE O DESTINO
}

\author{
Celi Hirata
}

RESUMO: Apresenta-se aqui a tradução do opúsculo Sobre o Destino (Von dem Verbängnisse), acompanhado de notas e comentário. Nele, Leibniz argumenta que todos os eventos no mundo são inteiramente determinados e que essa determinação deve ser motivo não apenas de tranquilidade, como também de regojizo da alma, constituindo o verdadeiro fundamento da religião. Como se pretende indicar no comentário ao texto, trata-se de um escrito bastante incomum pelo fato de que determinadas teses que são recorrentes na obra de Leibniz são articuladas e fundamentadas de maneira diversa, sem o recurso a Deus e à sua natureza bondosa.

PALAVRAS-CHAVE: Destino; causalidade; harmonia; religião.

\begin{abstract}
Here is presented the translation of the text On Destiny (Von dem Verbängnisse), accompanied by notes and a commentary. In this writing, Leibniz argues that all events in the world are entirely determined and that this determination should cause not only peacefulness but also rejoicing of the soul, constituting the true foundation of religion. As I intend to indicate in the commentary to the text, this writing is quite unusual by the fact that certain theses that are recurrent in Leibniz's work are articulated and grounded differently, without recourse to God and his goodness.
\end{abstract}

KEYWORDS: Destiny; Causality; Harmony; Religion. 


\section{Sobre o destino ${ }^{1}$}

Que tudo seja produzido por um destino fixo é tão certo como três vezes três é igual a nove. Pois o destino consiste em que tudo esteja conectado com tudo como numa cadeia e que algo ocorrerá de modo tão infalível antes de ocorrer como é infalível ocorrer quando ocorre.

Os poetas antigos, como Homero e outros, denominaram-no cadeia dourada, cadeia que Júpiter baixou do céu e que não pode se romper, independentemente do que se pendure nela. E essa cadeia consiste na consecução das causas e dos efeitos.

É que toda causa possui o seu efeito certo, que se produziria devido a ela, se estivesse sozinha; como, porém, não está só, então se produz a partir da cooperação de causas um certo efeito ou resultado infalível na medida das forças

${ }^{1}$ Originalmente, este pequeno opúsculo não apresentava nenhum título. O título "Von dem Verhängnisse" foi dado por G. E. Guhrauer, editor da coletânea de textos alemães de Leibniz (Deutsche Schriften, de 1840).

De acordo com o dicionário dos irmãos Grimm, "Verhängnis" refere-se àquilo que foi ordenado e decretado por um poder mais alto, sendo frequentemente traduzido por fatalidade ou destino (Deutsches Wörterbuch von Jacob und Wilhelm Grimm. Leipzig: 1854-1961. Disponivel em http://woerterbuchnetz.de e acessado em 22/08/2015). Preferi traduzir por "destino" para evitar o sentido pejorativo que a palavra "fatalidade" carrega, já que Leibniz dará um sentido positivo ao determinismo total de todos os eventos.

Na única ocorrência do termo dentre os textos editados por Gerhardt em Philosophischen Schriften, "Verhängnis" significa algo que é estabelecido para o gênero humano e aparece no mesmo contexto da graça divina, sendo que se deve saber tirar proveito dele - tal como Leibniz defenderá no Sobre o destino. "(...) es ist aber auch wahr, daßwenig seyn, so die vortheil wißen oder brauchen, und daß es gleichsam ein verhängnißfür das menschliche geschlecht, daß es die von Gott erzeigte gnade und schäze der güthigen Natur so wenig sich zu nuz macht"(trata-se de uma passagem de difícil compreensão, mas segue-se uma tradução livre: "é também verdadeiro que são poucos os que sabem utilizar ou tirar vantagem e proveito para si do, por assim dizer, destino estabelecido para o gênero humano, da graça manifestada por Deus e dos tesouros da natureza benfazeja"; Carta de Leibniz a Gabriel Wagner, sem data, in Philosophischen Schriften (doravante indicado pela sigla GP), VII, 518).

A tradução do texto foi realizada a partir da edição de Guhrauer (Deutsche Schriften, 48-55), mas se recorreu também à edição de Gerhardt (GP VII, 117-123), como será indicado em nota. Não se utilizou a versão apresentada por Grua por ser muito fragmentada (Textes Inédits, pp. 388-389). Ademais, comparou-se a tradução com aquela realizada por Roberto Torretti, publicada nos Escritos Filosóficos ( $\mathrm{p}$. 383-389). 


\section{Dossiê Leibniz, Dissertatio - Volume Suplementar 03 | UFPel [2016]}

presentes. E isso é verdadeiro não apenas quando duas, dez ou mil coisas cooperam, mas até mesmo quando infinitas coisas cooperam, como ocorre verdadeiramente no mundo.

A matemática ou a arte das medidas pode esclarecer essas coisas de um modo muito belo, já que tudo na natureza é, por assim dizer, circunscrito por número, medida, peso ou força. Quando, por exemplo, uma esfera colide com outra no ar e se sabe as suas dimensões, bem como a sua trajetória e percurso antes da colisão, pode-se prever e calcular como elas se chocarão e qual percurso tomará cada uma delas após o choque. Há disso regras muito belas, que também se confirmam ao se tomar quantas esferas se queira ou outras figuras além de esferas.

Por aí se vê que tudo se passa matematicamente, isto é, infalivelmente em todo o vasto mundo, de tal modo que, se alguém pudesse ter uma intuição das partes internas das coisas, além de memória e entendimento suficientes para examinar e levar em conta todas as circunstâncias, seria um profeta e veria o futuro no presente como num espelho.

Pois do mesmo modo que as flores e até mesmo os animais possuem já na semente uma constituição, embora algo aí possa ser alterado em virtude de algum outro acontecimento, pode-se dizer que todo o mundo futuro está contido e totalmente pré-formado no presente, uma vez que nenhum acontecimento externo pode suceder, pois não há nada fora dele. 
Mas para um entendimento limitado é impossível prever coisas futuras de modo circunstanciado, uma vez que o mundo é constituído por infinitas coisas que cooperam, de maneira que nada é tão pequeno nem tão distante que não contribua na sua medida. $\mathrm{E}$ tais coisas pequenas provocam frequentemente mudanças grandes e poderosas. Digo sempre que uma mosca poderia alterar todo um Estado se ficar zunindo na frente do nariz de um grande rei no momento de um conselho importante; pois pode ocorrer que o seu entendimento esteja, por assim dizer, em equilíbrio, já que se encontram fortes razões em favor de ambos os lados. Pode acontecer, então, que ganhem aquelas propostas que se detiveram por mais tempo em seu pensamento, e isso a mosca pode fazer, estorvando e perturbando-o quando ele quer considerar com justeza algo diferente, consideração que depois não retornará ao seu ânimo da mesma forma.

Aqueles que entendem alguma coisa de artilharia sabem como uma pequena mudança pode fazer com que uma bala mude completamente de percurso; daí ter sido devido a uma pequena mudança que Turenne, por exemplo, tenha sido atingido. E se isso não tivesse ocorrido, a guerra de outrora poderia ter se desenrolado de outra forma e as coisas hodiernas teriam, consequentemente, ocorrido de outro modo. Sabe-se também que uma faísca de fogo que cai num depósito de pólvora pode arruinar todo um mundo.

E esse efeito dos detalhes faz com que aqueles que não refletem bem sobre as coisas imaginem que algumas delas ocorram por acaso e não por destino, pois a diferença não se encontra no fato, mas apenas no nosso 


\section{Dossiê Leibniz, Dissertatio - Volume Suplementar 03 | UFPel [2016]}

entendimento, que não apreende a grande quantidade de detalhes que fazem parte de todo efeito, e não considera a causa que não vê, imaginando, assim, que as faces do dado caem ao acaso.

Essa infalibilidade do destino pode servir para tranquilizar o nosso ânimo. Afinal, quem tivesse pego dinheiro duas vezes, e, em cada uma delas, não mais do que mil tales, seria um insensato se depois se zangasse por encontrar em sua bolsa apenas dois mil tales e não três mil. Ora, do mesmo modo, na natureza tudo é proporcionado com justeza e exatidão. Ainda que pudesse dizer “mesmo assim estou zangado, precisamente por não ter pego mais de duas vezes mil tales, pois, se o tivesse feito três vezes, teria o que preciso agora", quem observa que a natureza inteira possui a sua justa medida conclui que, porque não se produz aquilo que não se encontrava anteriormente na natureza, é um disparate exigir isso dela, do mesmo modo que o é exigir que haja na bolsa aquilo que não foi colocado nela.

Alguém poderia, além disso, perguntar como pode ocorrer que a natureza inteira esteja constituída desde todo o sempre assim tal como a encontramos, visto que, de acordo com a nossa apreciação, ela poderia ser melhor. A resposta é que há sem dúvida também uma causa certa pela qual tudo na natureza tomou tal curso e nenhum outro. Eis porque, do mesmo modo que ficamos satisfeitos quando sabemos a causa pela qual a coisa deve ser, devemos nos esforçar sempre, tanto quanto possível, por satisfazer o nosso ânimo, pois 
sabemos que infalivelmente a causa está presente, mesmo que ainda não nos seja possível alcançar uma experiência circunstanciada de todas.

Mas nisto está contida uma causa ainda maior do nosso contentamento. Pois o contentamento ou quietude é de dois tipos: um se chama paciência (patience par force); o outro se chama regozijo e proporciona uma genuína satisfação com o sucedido; traz ao ânimo não apenas uma quietude ou tranquilidade, de modo que seu esforço não será em vão, mas também prazer e alegria. E alcançar isso nos momentos de adversidade é, apesar de difícil (porque não nos exercitamos nisto), em alguma medida factível, além de fundamentado nos fatos e na razão.

Isso porque julgamos que os números, figuras, forças e todas as coisas mensuráveis, das quais possuímos um conceito exato, são não apenas certos e infalíveis, mas também completamente ordenados e belos, e que, portanto, eles não podem ser melhorados e nem aquele que os compreende poderia desejar algo melhor.

Não podemos, contudo, ver tal ordem porque não nos encontramos no ponto de vista correto, de modo semelhante a uma pintura prospectiva, que só pode ser bem visualizada a partir de um determinado ponto, mas que de lado não se mostra com justeza.

Todavia, devemos nos posicionar com os olhos do entendimento onde não estamos e nem podemos estar com os olhos do corpo. Por exemplo, quando se observa o percurso das estrelas a partir da Terra — onde nos encontramos —, surge um ente estranho e confuso, e foi por isso que os astrônomos levaram 


\section{Dossiê Leibniz, Dissertatio - Volume Suplementar 03 UFPel [2016]}

alguns milhares de anos para a custo alcançarem algumas regras certas. E essas regras são tão difíceis e incômodas que um rei da Castela chamado Afonso, ao ordenar que uma tabela do percurso dos céus fosse calculada, teria dito, devido à falta de conhecimentos exatos, que, se ele tivesse sido conselheiro de Deus quando criou o mundo, as coisas deveriam ter se saído melhores.

Mas depois que finalmente se descobriu que se deve alocar o olho no Sol quando se quer observar com justeza o percurso dos céus, tudo então resulta maravilhosamente belo. E viu-se então que a suposta desordem e confusão era uma falha do nosso entendimento e não da natureza.

Deve-se, então, julgar que a mesma regularidade vige em todas as coisas com que nos deparamos. E, apesar de nem sempre acharmos imediatamente o ponto de vista correto com o entendimento, devemos nos regozijar, entretanto, por sabermos que, se nós o soubéssemos, nos satisfaríamos plenamente com todas as coisas. Devemos, portanto, ter desde já essa plena satisfação com as coisas, tal como nos satisfazemos plenamente com as ações de um amigo nosso ou de um príncipe quando temos uma firme confiança nele, isto é, quando estamos certos de seu entendimento e boa índole, ainda que não vejamos imediatamente e de uma vez por todas por que uma coisa ou outra ocorre e que frequentemente não pareçam exteriormente bem feitas.

E é precisamente essa plena satisfação com a suprema ordem geral, independentemente de como ela se desenvolve, quando cada um faz a sua parte, o genuíno fundamento da verdadeira religião. Desse modo, ela se fundamenta 
na razão e serve também ao nosso regozijo. ${ }^{2} \mathrm{E}$, do mesmo modo como não há quase nada tão agradável aos sentidos humanos quanto a harmonia na música, não há nada mais agradável do que a maravilhosa harmonia da natureza, da qual a música constitui apenas um antegosto e uma pequena amostra. Eis porque penso que aqueles espíritos elevados devem, quando lhes for facultado, procurar grande parte de seu prazer na investigação das maravilhosas obras da natureza e na busca das majestosas e belas verdades, nas quais estão contidas as retas ciências. As belas descobertas não apenas são gloriosas para aqueles que as fomentam, mas também incrementam a alimentação dos súditos, auxiliam no conforto da humanidade e até mesmo na manutenção da saúde. Mas, independentemente disto, elas lançam uma tal luz sobre a obra principal da natureza como um todo e daí nasce, como consequência, um tal regozijo, que aqueles que dela carecem são comparáveis àqueles que por todo o tempo precisam tatear no escuro; aqueles que, ao contrário, são iluminados por essas descobertas podem se alçar ao alto e a partir daí tudo observar, tal como os astros.

Se não fosse assim, seguir-se-ia que o conhecimento da verdade concernente ao principal não seria tão bom quanto a sua ignorância. Pois as pessoas ignorantes e supersticiosas contentam-se com toda espécie de imaginações falsas. Sendo assim, se da natureza não se devesse esperar nada de

\footnotetext{
${ }^{2}$ As edições de Guhrhauer e de Gerhardt divergem nessa passagem: o trecho que começa com "e, do mesmo modo como não há quase nada de tão agradável aos sentidos humanos do que a harmonia na música"e prossegue até"aqueles que, ao contrário, são iluminados por essas descobertas podem se alçar ao alto e a partir daítudo observar, tal como os astros"constitui os dois últimos parágrafos do texto na versão de Gerhardt. Optamos pela versão de Guhrhauer, apesar de ambas as ordens fazerem sentido.
} 


\section{Dossiê Leibniz, Dissertatio - Volume Suplementar 03 UFPel [2016]}

inteligente e virtuoso, então seria melhor ludibriar-se com outras coisas do que conhecer a verdade. No entanto, seria demasiado despropositado e repugnante a toda ordem se por fim se revelasse que a falta de entendimento poderia deixar em vantagem aqueles que por ela são acometidos. E como tudo na natureza possui a sua causa, de modo que tudo está ordenado, não pode ser, então, de outro modo: é preciso que o entendimento e a ação em consonância com o entendimento (isto é, a virtude) sejam melhores do que o contrário. Pois a natureza conduz tudo à ordem e aquele que já está mais próximo da ordem pode tanto mais facilmente lograr uma contemplação ordenada ou um conceito ordenado, isto é, chegar a um regozijo sensível, já que não pode haver regozijo maior do que se defrontar com os fatos e ver como tudo está bem e como nós não poderíamos desejar algo melhor.

A isso poderia ser objetado que muitos males acontecem e que, se tivéssemos que considerar como bem feito o que ocorreu, nenhuma maldade deveria ser punida. Mas deve-se ter em conta que o mal não é mau em si mesmo, mas apenas para aquele que o cometeu e isso inclui, portanto, a punição. Porém, considerando-se o todo, a natureza sabe extrair do pretenso mal o melhor, de tal maneira que tudo resulta muito melhor do que se sucedesse de outro modo; caso contrário ela certamente não iria permiti-lo. ${ }^{3}$ É verdade que nós preferiríamos que, além disso, não remanescesse nenhuma aparência de mal e que as coisas melhorassem, para que pudéssemos saber não apenas de maneira

\footnotetext{
${ }^{3} \mathrm{~A}$ primeira parte deste parágrafo foi traduzida a partir da edição de Gerhardt (GP VII, p.121), visto que nesta versão constam alguns trechos que estão ausentes no texto da edição de Guhauer.
} 
geral que tudo está bem e é bom, mas também pudéssemos compreendê-lo detalhadamente e até mesmo senti-lo efetivamente. Pois então o nosso regozijo seria maior e mais vívido, bem como nosso prazer, e teríamos tal compreensão e sensação, que todos os nossos pesares seriam mitigados e até mesmo aniquilados. Entretanto, devemos ter em consideração que isso não é factível de uma vez por todas e que é até mesmo melhor que seja assim. E, do mesmo modo como foi preciso o seu tempo até que a humanidade tenha descoberto que o ponto de vista correto da observação do percurso dos céus estava no Sol, deve-se considerar que a nossa alma, quando se dirige para isso, atingirá finalmente e gradualmente cada vez mais esse conceito e sensação da beleza da natureza na medida em que isso é factível.

E, mais ainda, uma vez que tudo está disposto da melhor maneira, deve-se, então, considerar que, antes e mais do que os outros, atingirão o regozijo dessa contemplação aqueles que, por meio do entendimento, se abriram mais para esse caminho, na medida em que dispuseram as suas ações de acordo com os seus melhores conceitos, com ordem ou segundo a razão, e para o bem, no que, aliás, consiste a virtude. De modo que também trabalham para a sua própria felicidade aqueles que fomentam sobretudo esse exame da verdade e das majestosas maravilhas da natureza suprema, que é eficaz por toda parte. Também o conhecimento correto assenta-se na compreensão que os homens possuem desse ponto capital, do qual dependem a virtude, o regozijo e a verdadeira felicidade. 
Chega-se, portanto, finalmente a estas duas grandes regras que a razão ensina por meio do próprio destino e da incomparável ordem que nele está contida: a primeira é que devemos já agora considerar todas as coisas passadas ou ocorridas como boas e bem feitas, como se já pudéssemos ver a partir do ponto de vista correto; a segunda é que devemos procurar, antes de tudo, fazer bem todas as coisas futuras e ainda não acontecidas, na medida em que dependem de nós e segundo os nossos melhores conceitos, de modo a seguirmos o mais próximo possível o ponto de vista correto. Aquela nos proporciona já todo o regozijo que é possível agora; esta nos abre o caminho para uma felicidade e alegria muito maiores.

\section{Comentário ao texto Sobre o Destino}

Segundo as estimativas de Gaston Grua, o texto Sobre o Destino teria sido redigido entre 1690 e 1697 e teria sido concebido como consolação para a duquesa de Orleans, Elisabeth Charlotte, que, por seu turno, teria se decepcionado com o seu conteúdo. ${ }^{4}$ Nele, Leibniz defende basicamente duas teses: em primeiro lugar, argumenta que todos os eventos no mundo são inteiramente determinados pelas suas causas antecedentes e, em segundo, que esse determinismo completo não deve ser motivo de desesperação, mas, muito pelo contrário, deve ser o fundamento de nossa inteira satisfação, uma vez que

${ }_{4}^{4}$ LEIBNIZ, Textes inédits, p. 388, nota 292. 
podemos estar assegurados desde já que todas as coisas são ordenadas e determinadas, sendo que o acaso está excluído do mundo.

Apesar de se tratar de dois temas centrais na filosofia de Leibniz (o determinismo completo do mundo e a satisfação que devemos ter em relação a ele), a articulação entre eles é diversa daquela que habitualmente se encontra nas obras mais famosas de Leibniz. Se, por um lado, o filósofo costuma conectar determinismo e satisfação, por outro, essa conexão costuma se dar por meio da afirmação da providência divina: na medida em que Deus, que é sumamente bom, justo e sábio, escolhe o melhor, e que há um dentre os mundos possíveis que é o melhor de todos, Deus o escolhe. Este mundo, por sua vez, é um conjunto determinado de substâncias, cada uma das quais possui um conjunto infinito de predicados que determinam tudo o que lhe diz respeito, de modo que o mundo é inteiramente determinado desde a sua criação. Como essa determinação completa de todas as coisas é decorrente do fato de que Deus escolheu o melhor dos mundos possíveis, essa determinação deve ser causa de alegria e não de desesperação, ainda mais porque essa determinação é inteiramente compatível com a contingência e a liberdade, tanto humana como a divina. No Sobre o Destino, ao contrário, o tema da providência divina e do melhor dos mundos possíveis está ausente. Embora faça alusão a uma causa inteligente do mundo ao dizer que se deve esperar algo de inteligente e virtuoso da natureza e que devemos nos comprazer com o mundo "tal como nos comprazemos com as ações de um amigo nosso ou de um príncipe quando temos uma firme confiança nele", o nome de Deus só aparece uma única vez, a 


\section{Dossiê Leibniz, Dissertatio - Volume Suplementar 03 | UFPel [2016]}

saber, quando Leibniz relata a anedota referente ao rei de Castela, que, levado pela ignorância e pela aparência de desordem no universo, afirmou que o mundo seria mais ordenado se ele tivesse sido o conselheiro de Deus.

No presente opúsculo, Leibniz não fundamenta a determinação total de todos os eventos no mundo em causas finais, mas em causas eficientes e mecânicas, ao afirmar que todos os efeitos são produzidos infalivelmente pela cooperação de causas e que o destino consiste na consecução encadeada de causas e efeitos. Tudo é matematicamente determinado, sendo que um homem que possuísse memória e entendimento suficientes para levar em conta todas as circunstâncias e calcular os seus resultados "seria um profeta e veria o futuro no presente como num espelho". Isso porque o universo constitui um sistema, sendo que tudo o que ocorrerá só pode ser consequência do que já está presentemente contido nele. É nesse sentido que a analogia parcial do mundo com as flores e os animais se aplica: tal como estes, que possuem uma constituição na semente, aquele já está pré-formado no presente; mas, diferentemente deles, não pode ser modificado a partir de uma causa exterior, uma vez que não há nada fora dele, de modo que está totalmente contido e préformado no presente. Pelo princípio de equipolência entre a causa plena e o efeito inteiro, formulado por Leibniz anos antes, em 1676, ${ }^{5}$ pode-se afirmar que há uma perfeita equivalência entre a causa e o seu efeito, sendo que entre eles

${ }^{5}$ Segundo FICHANT (1998, p. 180), a primeira formulação desse princípio se dá no De Arcanis Motus, de 1676. 
estabelece-se uma equação. ${ }^{6}$ Aplicando-se esse princípio ao mundo, pode-se dizer que o seu estado precedente, tal como numa máquina, "difere bem do precedente pela situação das potências, mas não pela sua soma", 7 sendo que há uma perfeita equivalência entre a potência do mundo no presente e no futuro. $\mathrm{O}$ advento de um fato no mundo cuja potência não estivesse contida nos seus estados precedentes violaria esse princípio: o efeito envolve a sua causa e a causa o seu efeito; o estado subsequente envolve o antecedente e o antecedente, o subsequente.

Essa tese da determinação total do mundo e da produção infalível de cada efeito a partir do concurso de suas causas eficientes foi fortemente influenciada pela filosofia de Hobbes, como indiquei mais detalhadamente em outro lugar. ${ }^{8}$ Para o filósofo inglês, causa e efeito são perfeitamente equalizáveis, na medida em que a presença da causa inteira equivale à produção de seu efeito e que um determinado efeito sinaliza que a causa que o produziu era completa, sendo que a soma de todos os requisitos necessários para que um evento se dê é igual à produção deste, sem qualquer espaço para a indeterminação. ${ }^{9}$ Com o

${ }^{6}$ Vide, por exemplo, Leibniz, carta a Bayle de 1687, pp. 45-6. Vale dizer que o princípio de equipolência entre a causa e 0 efeito aplica-se apenas à causalidade eficiente intramundana, e não à criação ou às causas finais, já que nesses casos a equivalência perfeita entre os termos da relação causal não se aplica. ${ }^{7}$ De concursu corporum, seção 7, in Fichant (1994), p. 145/tradução francesa: p. 293. No opúsculo Da origem primeira das coisas, Leibniz apresenta a relação entre a causa e o efeito como uma relação de semelhança (relação entre a cópia e o copiado) ao utilizar a metáfora da reprodução dos livros para exprimir a relação entre os estados subsequentes do mundo. Após introduzir a suposição de que o livro dos Elementos da Geometria tenha sido copiado sempre um do outro, Leibniz diz: "o que é verdadeiro quanto aos livros também se aplica aos vários estados do mundo, pois a situação seguinte é de certo modo copiada da precedente (ainda que com certas leis da mudança)" (LEIBNIZ, Da origem primeira das coisas, p. 155, itálicos meus).

${ }^{8}$ Cf. Hirata (2012), em especial, o primeiro capítulo.

9 Vide, por exemplo, Hobbes, De Corpore / Of Body, cap. 9. 


\section{Dossiê Leibniz, Dissertatio - Volume Suplementar 03 UFPel [2016]}

auxílio do conceito de conatus, que designa "o movimento feito num espaço e tempo menores do que podem ser dados", ${ }^{10}$ Hobbes afirma que todo movimento, por mais ínfimo e insensível que seja, tem o seu efeito devido, contribuindo de maneira necessária para a produção de um evento determinado. É assim que o movimento de um grão de areia distante — que é, em si mesmo, insensível para nós — contribui para a visão do monte de areia, constituindo um requisito indispensável para a produção desse efeito. E, invertendo-se o ponto de vista, "dificilmente há alguma ação, por mais casual que pareça, para cuja causação não concorra tudo o que esteja in rerum natura", 11 incluindo todos os pormenores. De maneira semelhante, Leibniz defende que não há algo que seja tão pequeno ou distante que não contribua na produção dos eventos do mundo, de modo que, inversamente, todo evento é rigorosamente determinado pela sua causa, que consiste numa infinidade de fatores. Rege no mundo um determinismo rigoroso de todos os eventos, um determinismo que opera no nível do infinitesimal, sendo cada detalhe decisivo: é assim que "uma mosca poderia alterar todo um Estado", influenciando na decisão de um rei ao perturbá-lo, ou que "uma faísca de fogo que cai num depósito de pólvora pode arruinar todo um mundo". Na medida em que vigora uma equação rigorosa entre causa e efeito, da mesma forma que nenhum efeito é incausado, nenhuma causa, por mais insignificante que pareça ser, permanece sem o seu devido efeito — "nada é tão pequeno nem tão distante que não contribua na sua medida". 
No Sobre o Destino, Leibniz enfatiza "este efeito dos detalhes": é apenas pela falta de observação deste que se crê que há coisas que ocorrem por acaso.

Contudo, se, por um lado, o filósofo alemão é fortemente influenciado por Hobbes quanto à tese do determinismo pela concorrência de todas as circunstância no mundo, por mais ínfimas que sejam, que compõem a causa integral e suficiente de todos os eventos, por outro, diferentemente do autor do Leviatã, Leibniz não defende em sua obra que todos os eventos são necessários ou que é impossível que ocorresse algo diverso do que efetivamente ocorre. Muito pelo contrário, sabemos que a defesa da tese da contingência dos fatos é um dos principais temas da filosofia leibniziana, já que, se o mundo fosse metafisicamente necessário, não haveria espaço para a liberdade, tanto humana quanto divina, e nem, consequentemente, para a determinação teleológica do mundo proveniente da escolha divina orientada para o melhor — o que Leibniz não poderia aceitar. O filósofo distingue completamente a tese do determinismo do mundo, — que ele endossa — e a tese da necessidade metafísica dos eventos mundanos, que rechaça: como defende amiúde, a determinação integral de todas as coisas tanto pelas suas causas eficientes como finais introduz apenas uma necessidade hipotética e moral, que é completamente compatível com a contingência e a liberdade, e de modo algum uma necessidade absoluta, lógica ou metafísica, já que outros fatos diferente dos que aconteceram ou acontecerão permanecem perfeitamente possíveis em si mesmos. ${ }^{12}$ Contudo, apesar do

12 Sobre este ponto, vide, por exemplo, Leibniz, Teodiceia, §2, 37, 43, 53, 230; Discurso de Metafísica, $\S 13$ e Sur la liberté. 


\section{Dossiê Leibniz, Dissertatio - Volume Suplementar 03 UFPel [2016]}

problema da contingência constituir um dos temas mais tratados na obra leibniziana (em especial quando a afirmação de que tudo está determinado é apresentada), ele está ausente no presente texto, de modo que alguém que lesse apenas o Sobre o Destino poderia pensar que, para Leibniz, todos os eventos no mundo são estritamente necessários, já que tradicionalmente determinismo e necessitarismo andam juntos.

Uma outra questão que se poderia colocar é se a causalidade produtora do destino é meramente eficiente ou é determinada teleologicamente. Afinal, Leibniz introduz a consideração acerca do melhor — ao levantar a hipótese de que alguém poderia se perguntar se as coisas não poderiam ser melhores e ao responder, no final do texto, que tudo está bem e não poderíamos desejar algo melhor — e afirma que a infalibilidade do destino deve conduzir não apenas à tranquilização, mas ao regojizo mesmo do ânimo com o mundo. O autor afirma que há na natureza ordem e harmonia, apesar da aparência de desordem, que nada mais é do que fruto de nossa falta de compreensão das coisas na sua totalidade. Se conseguíssemos alcançar o ponto de vista correto - como o alcançamos depois de muitos século em relação à astronomia com o heliocentrismo -, contemplaríamos a grande beleza do universo e alcançaríamos um grande regojizo. O argumento é semelhante àquele que será apresentado na Teodiceia e em outros textos, a saber, que a desordem é meramente aparente e que a realidade criada é a mais ordenada e harmônica possível, sendo que o nosso erro reside em julgarmos o todo pela parte. Além 
disso, da mesma maneira que na Teodiceia, Leibniz afirma que os males que constatamos existir conduzem a um bem maior: "considerando-se o todo, a natureza sabe extrair do pretenso mal o melhor, de tal maneira que tudo resulta muito melhor do que se sucedesse de outro modo; caso contrário ela certamente não iria permiti-lo." Trata-se, como se sabe, de um dos principais argumentos de que Leibniz lança mão para defender Deus da acusação de ser a causa do mal. O autor argumenta amiúde que Deus calcula e cria o conjunto de seres que possui o máximo de realidade com a maior ordem ou harmonia possível, sendo que esse conjunto compreende certos eventos que constituem em si mesmos males, como determinados pecados, por exemplo, sem os quais, no entanto, o maior bem possível do todo — a perfeição — não seria atingido. É verdade que Deus não quer nenhum mal, não quer que o homem peque, mas ele o permite na medida em que conduz a um bem maior. É nesse sentido que Leibniz distingue entre a vontade antecedente e a vontade consequente de Deus: pela primeira, que designa a vontade destacada, que considera cada bem enquanto bem, Deus quer que todos os homens sejam salvos; já pela segunda, que é a vontade final ou decretória e que consiste no resultado de todas as vontades antecedentes, Deus quer o melhor, o que envolve permitir alguns males que trazem benefícios maiores como consequência. ${ }^{13}$ Assim, Deus não quer o mal, mas o permite com base em razões superiores, para evitar um bem menor, que é considerado por Leibniz um mal. No Sobre o Destino, Leibniz também 


\section{Dossiê Leibniz, Dissertatio - Volume Suplementar 03 UFPel [2016]}

argumenta que os males são apenas permitidos a fim de que um bem maior se produza, mas o sujeito da ação não é Deus, mas a natureza. Tratam-se das mesmas justificativas para a existência do mal, só que sem Deus: "tudo está bem" e "não poderíamos desejar algo melhor", pois "a natureza conduz tudo à ordem" - é da própria natureza que se deve esperar algo de "inteligente e virtuoso". As razões para não apenas nos conformarmos, mas também nos satisfazermos e alegrarmos não repousam, pois, na providência divina — que nos asseguraria que, a despeito dos males, o mundo se encaminha para o melhor segundo um plano preestabelecido — mas na ordem e na harmonia da natureza. Há, por assim dizer, três fases da passagem do determinismo completo de todos os eventos a estados do ânimo daquele que o contempla. Em primeiro lugar, a consideração do destino leva à tranquilização (Berubigung) do ânimo, na medida em que é infalível e que tudo na natureza é proporcionado, fazendo com que não exijamos que a natureza produza aquilo para o que não concorrem as causas requisitadas — desse modo, escapamos à frustração e a todo esforço em vão. Em segundo, essa mesma consideração conduz à satisfação (Zufriedenheit) da alma, na medida em que podemos saber infalivelmente que, para todos os fatos, a causa está presente, mesmo que o conhecimento circunstanciado delas esteja fora de nosso alcance. É assim que nos asseguramos de que não há nenhum acaso nas coisas. Por fim, há uma causa ainda maior de satisfação — um regojizo (Vergnügung) que se opõe à mera paciência ou patience par force, como nos 
estoicos, ${ }^{14}$ por implicar não apenas quietude e tranquilidade, mas também prazer e alegria — na consideração da natureza do destino mesmo. Vimos que o que Leibniz chama de destino fundamenta-se na cadeia inquebrantável de causas que determina os seus efeitos de maneira exata, determinação que seria, ao menos de direito, passível de expressão matemática - tal como o princípio de equipolência entre a causa inteira e o efeito pleno já enunciava. Ora, como ele sustenta no Do Destino, "os números, figuras, forças e todas as coisas precisas das quais possuímos um conceito exato não são apenas certos e infalíveis" (motivo que leva à tranquilidade e satisfação da alma, como já se indicou), "mas também completamente ordenados e belos", o que é motivo de regojizo.

Aquilo que é de natureza matemática, da ordem do quantitativo, é investido pelo autor de conteúdo valorativo. De fato, em sua filosofia, Leibniz faz de alguma maneira o quantitativo o índice do qualitativo: dentre os outros infinitos possíveis, Deus calcula e cria o mundo no qual o máximo de efeitos é produzido com o mínimo de decretos, de acordo com uma relação matemática muito precisa: ${ }^{15}$ e este mundo, que se destaca isoladamente no ápice da pirâmide dos mundos possíveis, ultrapassando todos os demais em perfeição ${ }^{16}$, é escolhido por Deus devido à sua bondade e justiça. Por seu turno, os fenômenos deste mundo são regidos por uma ordem geométrica, de tal forma que as suas leis são passíveis de expressão matemática; essas leis, entretanto, só podem ser adequadamente fundamentadas no terreno da metafísica, pois é "a suprema

${ }_{14}^{14}$ LEIBNIZ, Princípios da Natureza e da Graça, §18; Discurso de Metafísica, §4.

${ }^{15} \mathrm{Cf}$. LEIBNIZ, Da origem primeira das coisas.

${ }^{16}$ LEIBNIZ, Teodiceia, §416. 


\section{Dossiê Leibniz, Dissertatio - Volume Suplementar 03 UFPel [2016]}

sabedoria de Deus" que "o fez eleger sobretudo as leis do movimento melhor ajustadas e que melhor convém às razões abstratas", leis pelas quais "a ação é sempre igual à reação e o efeito integral sempre equivale à sua causa plena". ${ }^{17} \mathrm{O}$ paradigma quantitativo da natureza típico dos modernos é subordinado ao qualitativo por meio da fundamentação da física na metafísica, que explica tanto a relação entre quantidade de realidade e ordem neste mundo, bem como o fato das leis físicas serem passíveis de compreensão pela matemática por meio da escolha divina orientada para o melhor, sendo que a ideia de bem é algo de absoluto que se encontra no entendimento divino desde toda a eternidade. No Sobre o Destino, porém, essa fundamentação metafísica está ausente.

Na continuação do texto, Leibniz afirma que a consequência de que os números, figuras, forças e todas as coisas mensuráveis e precisas sejam ordenados e belos é que "não há nada que possa ser melhorado neles e nem aquele que os compreende poderia desejar algo melhor". É verdade que nada pode ser melhorado nos números e em coisas de natureza semelhante, mas não porque se tratem de coisas que atendam o máximo possível o critério de bem, e sim porque se tratam de coisas absolutamente ou geometricamente necessárias, cujos contrários são absurdos ou impossíveis. No que diz respeito ao que é do domínio da matemática ou da geometria, não há outras alternativas possíveis além daquilo que é, de modo que não há espaço para escolhas e, consequentemente, para o estabelecimento de finalidades. É nesse sentido que

${ }_{17}$ LEIBNIZ, Princípios da Natureza e da Graça, §11, p. 159. 
Leibniz argumentará em 1715 que Clarke está errado em dizer que os meros princípios matemáticos combatem o materialismo, pois os princípios de contradição e de identidade (sobre os quais as matemáticas se fundamentam) só determinam se algo é verdadeiro ou não, necessário ou contraditório, sem qualquer espaço para considerações morais ou finalistas. ${ }^{18} \mathrm{~A}$ física, na medida em que tem como objeto a criação divina, deve, ao contrário, ser fundamentada no princípio de razão suficiente, que busca justificar os fatos principalmente (ainda que não somente) em razões de caráter teleológico.

Se em vários textos Leibniz se esforça em defender a tese da contingência dos fatos, apesar da determinação integral de todos os eventos, para fundamentar não apenas a possibilidade de livre-arbítrio nos homens e criaturas racionais em geral, mas também a tese do mundo como produto da escolha divina orientada para o melhor, no Sobre o Destino, o contentamento da alma advém tão-somente da ordenação mecânica e matemática do mundo. É como se o simples fato de tudo ser determinado matematicamente a partir do concurso das causas eficientes, sem qualquer espaço para o acaso, fosse algo bom que justificasse a nossa satisfação em relação a este mundo. O mero dado de haver uma ordem que poderia ser compreendida por quem tivesse entendimento suficiente, mesmo que fosse necessária, já satisfaria o ânimo. Afinal, é totalmente descabido querer outra ordem de coisas, ordem em relação à qual não cabe nenhuma melhoria, uma vez que (assim parece) ela não pode 


\section{Dossiê Leibniz, Dissertatio - Volume Suplementar 03 | UFPel [2016]}

ser outra - não causa admiração, assim, que a duquesa de Orleans tenha se decepcionado. Se, por um lado, Leibniz parece conferir um caráter teleológico à determinação completa de todos os eventos a partir do encadeamento das causas eficientes, por outro, poder-se-ia perguntar se esse caráter seria compatível com essa ordenação estritamente matemática das coisas.

Por fim, a partir desse determinismo e do contentamento da alma que lhe é correspondente, Leibniz estabelece um fundamento puramente intelectual para a moral e a religião. Segundo o autor, "o legítimo fundamento da verdadeira religião" não é a fé em Cristo, mas “esse comprazimento com a suprema ordem geral, independentemente de como ela se desenvolve". É certo que um dos principais objetivos de Leibniz na sua obra como um todo (em especial na Teodiceia) é contrapor-se aos fideístas e demonstrar que os dogmas do Cristianismo não são contrários à razão, mas estão de acordo com ela:19 tratase, porém, justamente de compatibilizar a razão com a fé , que, apesar de ser de direito conciliável com a razão, na medida em que duas verdades (aquelas reveladas nas sagradas Escrituras e aquelas descobertas pela razão) não podem se contradizer, é-lhe irredutível: afinal, há artigos de fé, os mistérios, que estão acima da razão das criaturas, mesmo que não possam ser-lhes contrárias. ${ }^{20}$ Por isso, a religião não pode ser inteiramente fundamentada na razão humana, por mais que possa ser corroborada por ela. No Sobre o Destino, no entanto, Leibniz 
parece se referir a uma religião natural e inteiramente racional, sem nenhuma referência à fé.

Uma vez que a religião se fundamenta na razão, as ciências adquirem uma função que não é meramente teórica e técnica, mas também prática: não apenas auxiliam no bem-estar material dos homens, contribuindo para a sua alimentação, saúde e conforto em geral, mas também iluminam os seus praticantes, conduzindo à verdadeira felicidade, por levá-los ao regojizo e ao saber de que não se poderia desejar nada de melhor. Aquele que é inteligente e virtuoso encontrará, por sua vez, algo análogo à inteligência e à virtude na natureza, sendo que a virtude define-se justamente como a ação em consonância com o entendimento ou a disposição das ações de acordo com os melhores conceitos de que se dispõe ou segundo a razão. A boa ação depende, assim, do entendimento e da razão. Com base nisso, Leibniz formula duas regras práticas: a primeira, que diz respeito ao passado, nos prescreve a considerar tudo que ocorreu como bom, “como se já pudéssemos ver a partir do ponto de vista correto", apesar de nossa limitação; a segunda, que se dirige ao futuro, nos ordena a seguir "o mais próximo possível o ponto de vista correto" e a agir com base nele. Assim, é do ponto de vista correto que dependem não apenas o conhecimento e o desenvolvimento da ciência, mas também a religião, a virtude e a felicidade.

O Sobre o Destino é, enfim, um opúsculo que apresenta temas que são muito recorrentes na obra de Leibniz — como o determinismo integral de todos os eventos do mundo, a ordem e a harmonia da natureza, as razões de 
contentamento da alma com o mundo, a afirmação de que não se poderia desejar nada de melhor, a justificativa da existência do mal a partir do argumento de que ele serve para a extração de um bem maior, o acordo da religião com a razão, a exaltação das ciências e uma moral fortemente intelectualista —, mas no qual o elemento central que fundamenta todos esses temas está ausente: Deus. Como comenta Ezequiel de Olaso, o Sobre o Destino parece um tratado pagão escrito por um estóico bruscamente alegre," ${ }^{21}$ bem diferente do Leibniz cristão com o qual estamos acostumados.

\section{BIBLIOGRAFIA}

FICHANT, Michel. La réforme de la dynamique. Paris: Vrin, 1994. . Science et métaphysique dans Descartes et Leibniz. Paris: PUF, 1998.

GRIMM, Jacob e Wilhelm. Deutsches Wöterbuch von Jacob und Wilhelm Grimm. Leipzig: 1854-1961. Disponível em http://woerterbuchnetz.de e acessado em 22/08/2015.

HIRATA, Celi. Leibniz e Hobbes: causalidade e princípio de razão suficiente. Tese (Doutorado em Filosofia) - Faculdade de Filosofia, Letras e Ciências Humanas, Universidade de São Paulo, São Paulo, 2012.

${ }^{21}$ LEIBNIZ, Escritos Filosóficos, p. 380. 
HOBBES, Thomas. Concerning Body. In: MOLESWORTH, W. (ed.). English Works. Darmstadt: Schrecker, 1966 (2ª edição), vol I. . The questions concerning liberty, necessity, and chance. In: English Works, vol. V.

LEIBNIZ, Gottfried Wilhelm. Von dem Verbängnisse. In: Deutsche Schriften. Hildesheim: Olms, vol. 2, pp. 48-55, 1966.

. Von dem Verbängnisse. In: GEHARDT (ed.). Die Philosophischen Schriften von Gottried Wilhelm Leibni;. Berlim: Georg Olms Hildesheim, vol.VII, pp. 117-123 1960.

.Von dem Verbängnisse. In: GRUA, G. (ed.). Textes inédits d'après les manuscrits de la Biliothèque provinciale de Hanovre. 2 volumes. Paris: PUF, pp. 388389, 1998.

. Del Destino. OLASO, E. (ed.). G. W. Leibniz: Escritos Filosoficos.

Buenos Aires: Editorial Charcas, pp. 383-389, 1982.

. Carta a Bayle de 1687. In: Die Philosophischen Schriften von Gottfried Wilhelm Leibniz, vol. 3, pp. 42-49.

Correspondência com Clarke. In:Newton/ Leibniz: Os Pensadores. São Paulo: Abril, pp. 167-232, 1983. 
- Da Origem Primeira das Coisas. In: Os Pensadores, pp. 153-161. . De Concursu Corporum. In: La réforme de la dynamique, pp. 69-171.

. Diálogo entre un Teólogo y un Misósofo. In: Escritos Filosóficos, pp. 209-217. . Discurso de Metafísica. In: Discurso de Metafísica e outros textos. São Paulo: Martins Fontes, pp. 1-79, 2004.

. Essais de Théodicée sur la bontéode Dieu, la libertéide l'bomme et l'origine du mal. In: Die Philosophischen Schriften von Gottfried Wilhelm Leibniz, vol. 6, pp. 3-375. - Princípios da Natureza e da Graça Fundados na Razão. In: Discurso de Metafisica e outros textos, pp. 151-163.

. Sur la liberté. In: RAUZY, J.(ed.). Recherches générales sur l'analyse des notions et des vérités: 24 thèses métaphysiques et autres textes logiques et métaphysiques. Paris: PUF, pp. 329-335, 1998. 